\title{
H/D isotope effect and magnetic properties of cyanide-bridged Nd(III)-Fe(III) complex
}

\author{
By T. Akitsu ${ }^{1, *}$, Y. Kimoto ${ }^{1}$, Y. Yamada ${ }^{1}$ and K. Nomura ${ }^{2}$ \\ ${ }^{1}$ Department of Chemistry, Faculty of Science, Tokyo University of Science, 1-3 Kagurazaka, Shinjuku-ku, Tokyo 162-8601, Japan \\ ${ }^{2}$ Graduate School of Engineering, The University of Tokyo, 7-3-1 Hongo, Bunkyo-ku, Tokyo 113-8565, Japan
}

(Received October 1, 2009; accepted in revised form December 20, 2010)

\section{$\mathrm{Nd}(\mathrm{III}) / \mathrm{Fe}(\mathrm{III}) / \mathrm{H} / \mathrm{D}$ isotope / Magnetism / \\ Negative thermal expansion}

Summary. We have prepared four $\mathrm{H} / \mathrm{D}$ isotope forms of $\mathrm{Nd}(\mathrm{DMF})_{4}\left(\mathrm{H}_{2} \mathrm{O}\right)_{3} \mathrm{Fe}(\mathrm{CN})_{6} \cdot \mathrm{H}_{2} \mathrm{O}$ (DMF $=N, N$-dimethylformamide) by using $\mathrm{D}_{2} \mathrm{O}$ or DMF-d1. Temperature dependence of magnetization exhibits H/D isotope effects resulting from intermolecular hydrogen bonds. Temperature dependence of $\mathrm{Fe} 2 p_{3 / 2}$ and $2 p_{1 / 2}$ XAS and ${ }^{57} \mathrm{Fe}$ Mössbauer spectra suggested that the influence of coordination environment could be distiguished from the influence of crystal lattice based on preliminary crystallographic results.

\section{Introduction}

During searching for photo-controllable molecule-based magnets, we discovered $\mathrm{Nd}(\mathrm{DMF})_{4}\left(\mathrm{H}_{2} \mathrm{O}\right)_{3} \mathrm{Fe}(\mathrm{CN})_{6} \cdot \mathrm{H}_{2} \mathrm{O}$ (Fig. 1) as the first desirable material among $3 d-4 f$ cyanobridged complexes [1]. Although its magnetic properties [2] and photo-induced excited structure [3] have been investigated, the reason why only it exhibits such a property has not been elucidated so far. We have systematically studied on structure-function correlation of the related compounds and application for hybrid functional materials widely [4-12].

Herein we prepared four forms of the $\mathrm{H} / \mathrm{D}$ isotopic isomers of $\mathrm{Nd}(\mathrm{DMF})_{4}\left(\mathrm{H}_{2} \mathrm{O}\right)_{3} \mathrm{Fe}(\mathrm{CN})_{6} \cdot \mathrm{H}_{2} \mathrm{O}$ ( $\mathrm{HH}$ denotes a complex with $\mathrm{H}_{2} \mathrm{O}$ and DMF; DH denotes $\mathrm{D}_{2} \mathrm{O}$ and DMF; $\mathrm{HD}$ $\mathrm{H}_{2} \mathrm{O}$ or $\left(\mathrm{CH}_{3}\right)_{2} \mathrm{NCDO}$ (DMF-d1); DD denotes $\mathrm{D}_{2} \mathrm{O}$ and DMF-d1). In this communication, we examined field and temperature dependence of magnetization to discuss the influence of the intermolecular hydrogen bonds (which will not be strong superexchange interaction thourgh cyanide bridges), and temperature dependence of $\mathrm{Fe} 2 p_{3 / 2}$ and $2 p_{1 / 2}$ soft X-ray absorption spectra (XAS) to discuss inner shell electronic states of $\mathrm{Fe}$ ions. We also examined the temperature dependence of ${ }^{57} \mathrm{Fe}$ Mössbauer spectra to discuss closely in view of (i) H/D isotope effects and (ii) separation thermal vibration of $\mathrm{Fe}$ atoms and lattice strain. According to preliminary crystal structure determination (unpublished results), $\mathrm{Nd}(\mathrm{DMF})_{4}\left(\mathrm{H}_{2} \mathrm{O}\right)_{3} \mathrm{Fe}(\mathrm{CN})_{6} \cdot \mathrm{H}_{2} \mathrm{O}$ indicates anisotropic negative thermal expansion along the $a$-axis in the range of 100-150 K, which reflects specific changes of

\footnotetext{
*Author for correspondence (E-mail: akitsu@rs.kagu.tus.ac.jp).
}

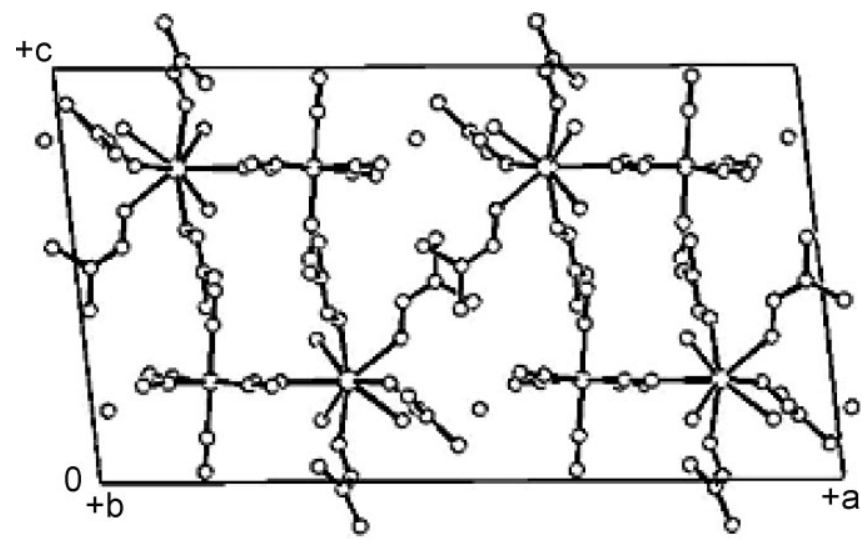

Fig. 1. Crystal structure of $\mathrm{HH}$ of $\mathrm{Nd}(\mathrm{DMF})_{4}\left(\mathrm{H}_{2} \mathrm{O}\right)_{3} \mathrm{Fe}(\mathrm{CN})_{6} \cdot \mathrm{H}_{2} \mathrm{O}$.

coordination bonds around $\mathrm{Fe}$ and $\mathrm{Nd}$ atoms. On the other hand, specific intermolecular hydrogen bond distances are not identical among $\mathrm{HH}, \mathrm{DH}, \mathrm{HD}$, and $\mathrm{DD}$ forms at constant temperature. Mössbauer spectra indicated that low-spin $\mathrm{Fe}(\mathrm{III})$ states were kept for all the conditions.

\section{Experimental section}

Four H/D isotope complexes (abbreviated as HH, DH, HD, and $\mathrm{DD}$ ) were prepared by using the corresponding $\mathrm{D}_{2} \mathrm{O}$ and DMF-d1 solvents according to the literature [1]. ${ }^{57} \mathrm{Fe}$ isotope was not enriched for all the samples served for Mössbauer spectroscopy.

The magnetic properties were measured with a Quantum Design MPMS-XL superconducting quantum interference device (SQUID) magnetometer at $0-50000 \mathrm{G}$ at $5 \mathrm{~K}$ and at $5-300 \mathrm{~K}$ at $5000 \mathrm{G}$.

The Fe $2 p_{3 / 2}$ and $2 p_{1 / 2}$ XAS were measured at KEK PF BL-19B under variable temperature. The spectra were corrected by the standard Au sample.

Mössbauer spectra of the samples at room temperature were measured in a transmission geometry using a ${ }^{57} \mathrm{Co} / \mathrm{Rh}$ source and a Wiessel MDU1200 transducer. Variable temperature Mössbauer spectra were recorded by a conventional constant-acceleration spectrometer with a ${ }^{57} \mathrm{Co} / \mathrm{Cr}$ source and cryostat. The Doppler velocity was calibrated by using $\alpha$-Fe foil. 


\section{Results and discussion}

Fig. 2 shows the field dependence of magnetization at $5 \mathrm{~K}$ (above) and temperature dependence of magnetization at $5000 \mathrm{G}$ for $\mathrm{HH}, \mathrm{DH}, \mathrm{HD}$, and $\mathrm{DD}$. As reported previously [2], $\mathrm{Nd}(\mathrm{DMF})_{4}\left(\mathrm{H}_{2} \mathrm{O}\right)_{3} \mathrm{Fe}(\mathrm{CN})_{6} \cdot \mathrm{H}_{2} \mathrm{O}$ exhibited antiferromagnetic interaction through cyanide-bridged superexchange interactions, which was confirmed comparison with $\mathrm{Nd}(\mathrm{DMF})_{4}\left(\mathrm{H}_{2} \mathrm{O}\right)_{3} \mathrm{Fe}(\mathrm{CN})_{6} \cdot \mathrm{H}_{2} \mathrm{O}$ and $\mathrm{La}(\mathrm{DMF})_{4}\left(\mathrm{H}_{2} \mathrm{O}\right)_{3} \mathrm{Co}-$ $(\mathrm{CN})_{6} \cdot \mathrm{H}_{2} \mathrm{O}$. In addition, the role of intermolecular hydrogen bonds has been also stated in the previous study [2]. Although the field dependence of magnetization plot reflecting magnetic ordering exhibits slight difference among the four $\mathrm{H} / \mathrm{D}$ isomer, the temperature dependence of magnetization plot reflecting magnetic interaction exhibits distinct difference as temperature increasing. The introduction of D in the hydrogen bond network, which is in harmony with site geometries from a preliminary crystallographic study.

Fig. 3 exhibits $\mathrm{Fe} 2 p_{3 / 2}$ and $2 p_{1 / 2} \mathrm{XAS}$ at various temperature for $\mathrm{HH}$. This spectral information is ascribed to temperature dependence of local coordination environment around $\mathrm{Fe}$ ions as well as electronic states. As shown in Fig. 4, low-spin Fe(III) state is also conserved for DH, as is
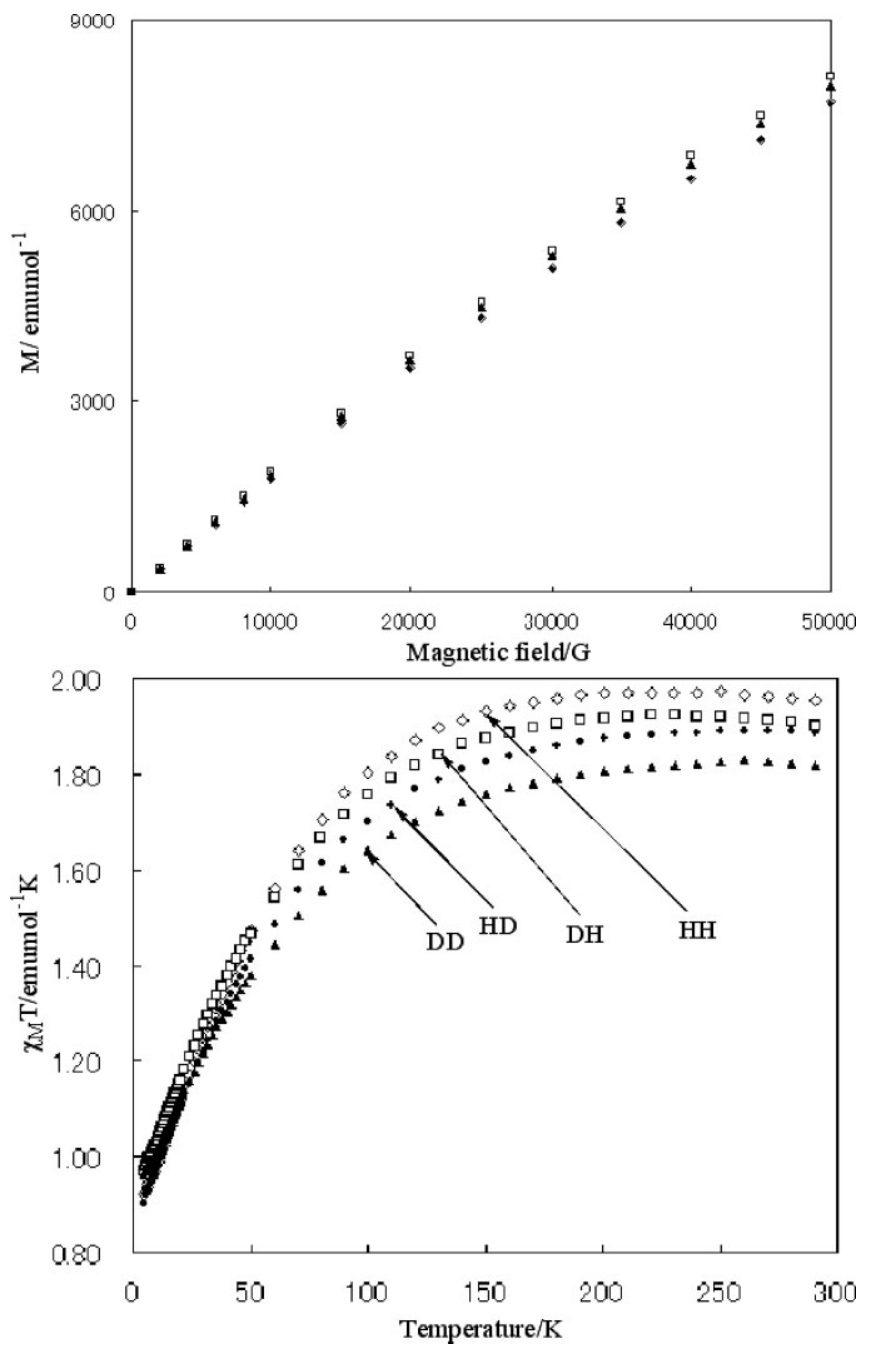

Fig. 2. Field dependence of magnetization at $5 \mathrm{~K}$ (above) and temperature dependence of magnetization at $5000 \mathrm{G}$ the for $\mathrm{HH}, \mathrm{DH}, \mathrm{HD}$, and DD (below).

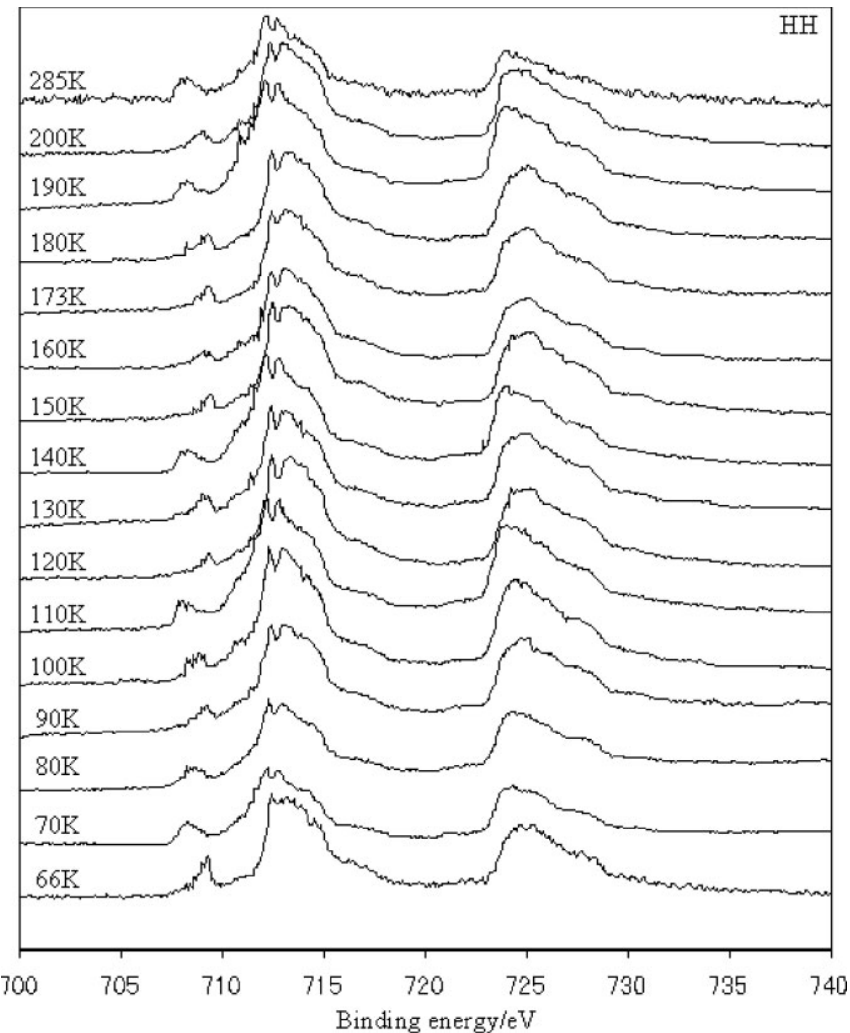

Fig. 3. Variable temperature soft X-ray absorption spectra of $\mathrm{Fe} 2 p_{3 / 2}$ and $\mathrm{Fe} 2 p_{1 / 2}$ for $\mathrm{HH}$.

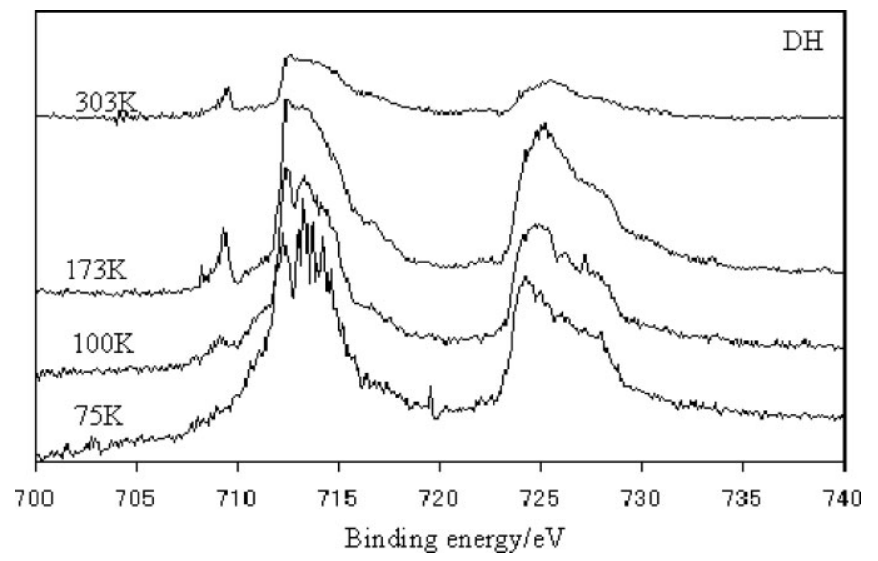

Fig. 4. Variable temperature soft X-ray absorption spectra of $\mathrm{Fe} 2 p_{3 / 2}$ and $\mathrm{Fe} 2 p_{1 / 2}$ for $\mathrm{DH}$.

$\mathrm{HH}$, and little $\mathrm{H} / \mathrm{D}$ isotope effect can be observed by means of XAS.

Fig. 5 shows Mössbauer spectra of HH and HD at room temperature, at which conditions, the temperature dependence of magnetization plot exhibits distinct differences. In contrast to magnetization measurements, H/D isotope effect on intermolecular hydrogen bonds of DMF moiety is too slight to detect local changes of coordination by means of Mössbauer spectroscopy.

Fig. 6 summarizes Mössbauer parameters [qudrupole splitting (Q.S.), isomer shift relative to $\alpha$-iron foil at room temperature (I.S.), and experimental line width (H.W.)] for $\mathrm{HH}$ and $\mathrm{DH}$ at $300,173,100$, and $12 \mathrm{~K}$. Although slight difference between $\mathrm{HH}$ and DH appears, low-spin $\mathrm{Fe}(\mathrm{III})$ state is conserved for all the data points. Accord- 


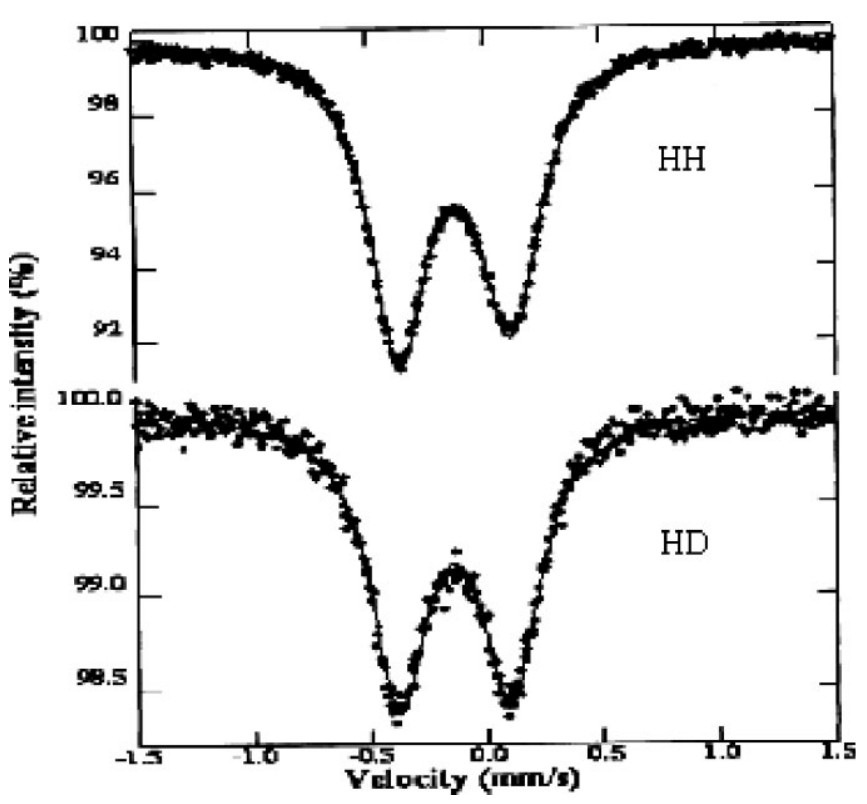

Fig. 5. ${ }^{57} \mathrm{Fe}$ Mossbauer spectra of $\mathrm{HH}$ and $\mathrm{HD}$ at $300 \mathrm{~K}$.
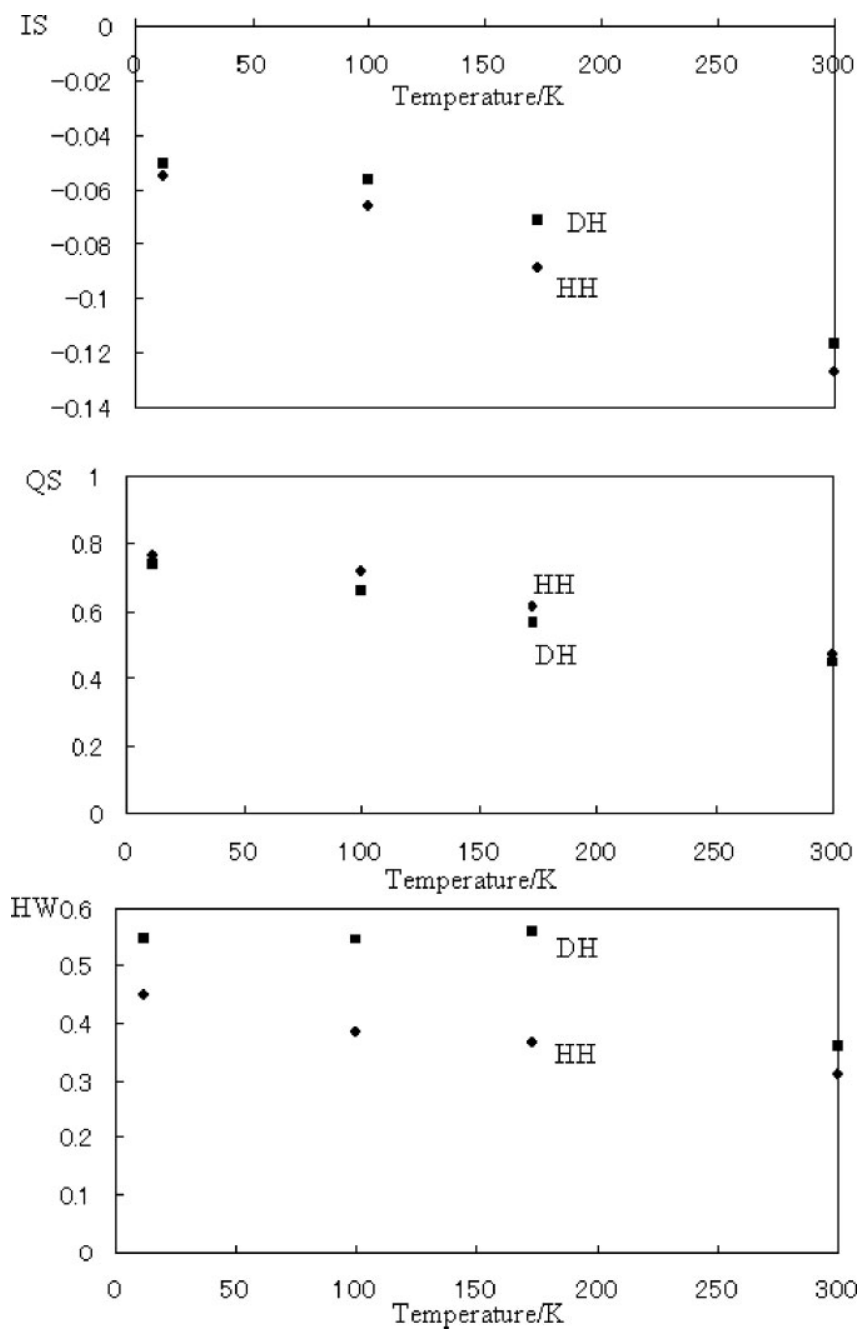

Fig. 6. Temperature dependence of IS (above), QS (middle) and HW (below) parameters of ${ }^{57} \mathrm{Fe}$ Mossbauer spectra for $\mathrm{HH}$ and $\mathrm{DH}$.

ing to crystallographic results, (anisotropic) displacement parameters of $\mathrm{Fe}$ atoms associated with thermal vibration become small on cooling monotonously, while lattice pa- rameters exhibit anisotropic negative thermal distortion in the range of 100-150 K. In this way, unusual structural behavior emerges from thermally-accessible lattice changes for both DD and DH. Furthermore, the mechanism of negative thermal expansion for $\mathrm{Nd}(\mathrm{DMF})_{4}\left(\mathrm{H}_{2} \mathrm{O}\right)_{3} \mathrm{Fe}(\mathrm{CN})_{6} \cdot \mathrm{H}_{2} \mathrm{O}$ is not well-known losing crystalline water molecules nor phase transition, which results in drastic changes of Mössbauer spectra.

Comparison with other systems of local distortion of coordination environment and global strain of crystal lattice may help to understand characteristics of the present results. For example, Jahn-Teller distortion of $\mathrm{Cu}$ (II) ions is wellknown factors for local distortion by flexible coordination environment. Besides $\mathrm{Cu} \mathrm{B}$ and heme $\mathrm{a}_{3}$ active sites in cytochrome c oxidase [13], $\mathrm{Cu}-\mathrm{Fe}$ bimetallic systems are of frequent occurrence in inorganic chemistry. Combination of Jahn-Teller effect of $\mathrm{Cu}$ sites and valence or spin states of Fe sites can induce various structural and electronic features. Recently, Long et al. [14] reported thermally-induced isostructural phase transition of $\mathrm{LaCu}_{3} \mathrm{Fe}_{4} \mathrm{O}_{12}$ perovskite above room temperature. Redhammer et al. [15] discussed temperature-dependent crystal structure refinement and ${ }^{57} \mathrm{Fe}$ Mössbauer spectroscopy of $\mathrm{Cu}_{2} \mathrm{Fe}_{2} \mathrm{Ge}_{4} \mathrm{O}_{13}$ garmanate. These two oxides exhibit phase transition and negative thermal expansion, anisotropically specific axis length decreasing on heating by several mechanism for each system [16]. Negative thermal expansion exhibits opposite structural response against common systems by changing temperature, because it may be useful examples to examine temperature dependent correlation between crystal structures and electronic properties [17].

Deconvolution of Mössbauer spectra provides quadrupole splitting parameters [18], isomer shift parameters, and half width values. Contrary to theoretical calculations of Mössbauer parameters [19-21], the influence of crystal lattice is not negligible for actual systems. Some reasons showing drastic changes of Mössbauer spectra accompanying changes of crystal lattice have been reported experimentally such as thermal decomposition losing crystalline water [22], dimorphism [23] and low-temperature crystal structure, light-induced magnetic excited state [24], and phase transition of $\mathrm{Fe}(\mathrm{II})$ ions in a quasicubic environment [25].

Classically, lattice dynamics studies on influence of (intermolecular) bridges and temperature dependence of asymmetric ${ }^{119} \mathrm{Sn}$ Mössbauer spectra have been developed for halogeno-bridged coordination polymers [26-28]. The main and important idea of this treatment is that scattering of $\gamma$-ray depends on thermal displacement $\left\langle\mathrm{U}_{z}^{2}\right\rangle$ of $\mathrm{Sn}$ atoms, which is combined with lattice strain directly.

Thus, temperature, crystal lattice, and thermal displacement of atoms decide Mössbauer parameters in this system.

\section{Concluding remarks}

We have investigated $\mathrm{H} / \mathrm{D}$ isotope effects of $\mathrm{Nd}(\mathrm{DMF})_{4}$ $\left(\mathrm{H}_{2} \mathrm{O}\right)_{3} \mathrm{Fe}(\mathrm{CN})_{6} \cdot \mathrm{H}_{2} \mathrm{O}$ and their thermal-responses. Although the $\chi_{\mathrm{M}} T$ vs. $T$ plot exhibits $\mathrm{H} / \mathrm{D}$ isotope effect against intermolecular hydrogen bonds, this influence cannot change low-spin Fe(III) electronic state. Conservation of low-spin $\mathrm{Fe}(\mathrm{III})$ electronic state is also supported $\mathrm{Fe} 2 p_{3 / 2}$ and $2 p_{1 / 2}$ 
XAS about local information of Fe atoms. Crystallographic study is in progress now.

Acknowledgment. We are gratefully acknowledged to the Materials Design and Characterization Laboratory, Institute for Solid State Physics, the University of Tokyo for the use of the SQUID facilities and KEKPF BL-19B (2008G528) for soft X-ray spectroscopy using synchrotron radiation.

\section{References}

1. Li, G., Akitsu, T., Sato, O., Einaga, Y.: J. Am. Chem. Soc. 125, 12396 (2003)

2. Figuerola, A., Diaz, C., Ribas, J., Tangoulis, V., Granell, J., Lloret, F., Mahia, J., Maestro, M.: Inorg. Chem. 42, 641 (2003).

3. Svendsen, H., Overgaard, J., Chevallier, M., Collet, E., Iversen, B. B.: Angew. Chem. Int. Ed. 48, 2780 (2009).

4. Li, G., Sato, O., Akitsu, T., Einaga, Y.: J. Solid State Chem. 177, 3835 (2004).

5. Li, G., Akitsu, T., Sato, O., Einaga, Y.: Hyperfine Interact. 156/ 157, 143 (2004).

6. Akitsu, T., Einaga, Y.: Polyhedron 25, 2655 (2006).

7. Akitsu, T., Einaga, Y.: Inorg. Chim. Acta 359, 1421 (2006).

8. Akitsu, T., Einaga, Y.: Asian Chem. Lett. 10, 95 (2006).

9. Akitsu, T., Einaga, Y.: Asian Chem. Lett. 10, 113 (2006).

10. Akitsu, T., Einaga, Y.: Asian Chem. Lett. 10, 121 (2006).

11. Akitsu, T., Einaga, Y.: Chem. Pap. 61, 194-198 (2007).

12. Akitsu, T., Nishijo, J.: J. Magn. Magn. Mater. 320, 1586 (2008).
13. Tsukihara, T., Shimokata, K., Katayhama, Y., Shimada, H., Muramoto, K., Aoyama, H., Mochizuki, M., Shinzawa-Itoh, K., Yamashita, W., Yao, M., Ishimura, Y., Yoshikawa, S.: Proc. Natl. Acad. Sci. USA 100, 15304 (2003).

14. Long, Y. W., Hayashi, N., Saito, T., Azuma, M., Muranaka, S., Shimakawa, Y.: Nature 458, 60 (2009).

15. Redhammer, G. J., Merz, M., Tippelt, G., Sparta, K., Roth, G., Treutmann, W., Lottermoser, W., Amthauer, G.: Acta Crystallogr. B 63, 4 (2007).

16. Goodwin, A. L., Calleja, M., Conterio, M. J., Dove, M. T., Evans, J. S. O., Keen, D. A., Peters, L., Tucker, M. G.: Science 319, 794 (2008).

17. Lukaszewicz, K., Pietraszko, A., Stepien-Damm, J., Kajokas, A., Grigas, J., Drulis, H.: J. Solid. State. Chem. 162, 79 (2001).

18. Bancroft, G. M.: Coord. Chem. Rev. 11, 247 (1973).

19. Filatov, M.: Coord. Chem. Rev. 253, 594 (2009).

20. Nemykin, V. N., Hadt, R. G.: Inorg. Chem. 45, 8297 (2006).

21. Romelt, M., Ye, S., Neese, F.: Inorg. Chem. 48, 784 (2009).

22. Gallagher, P. K., Kurkjian, C. R.: Inorg. Chem. 5, 214 (1966).

23. Leone, P., Palvadeau, P., Boubekeur, K., Meershaut, A., Bellitto, C., Bauer, E. M., Righini, G., Fabritchnyi, P.: J. Solid State Chem. 178, 1125 (2005).

24. Rusanov, V.: Stankov, S., Ahmedova, A., Trautwein, A. X.: J. Solid State Chem. 182, 1252 (2009).

25. Carver, G., Dobe, C., Jensenn, T. B., Tregenna-Piggott, P. L. W., Janssen, S., Bill, E., Mclntyre, G. J., Barra, A.-L.: Inorg. Chem. 45, 4695 (2006).

26. Moreno, M. S., Mercader, R. C.: Phys. Rev. B 50, 9875 (1994).

27. Stockler, H. A., Sano, H.: Phys. Rev. 165, 406 (1968).

28. Stockler, H. A., Sano, H.: Chem. Phys. Lett. 2, 448 (1968). 